\title{
DIALÉTICA, EXPERIÊNCIA E INTUIÇÃO: ENTRE HERMENÊUTICA FILOSÓFICA E FILOSOFIA BUDISTA*
}

\author{
Luiz Rohden** \\ rohden@unisinos.br \\ Leonardo Marques Kussler*** \\ leonardo.kussler@gmail.com
}

Isto é hermenêutica, o quanto fica, sempre, de não dito quando se diz algo. (Gadamer)

RESUMO Hans-Georg Gadamer retomou e elevou a atividade hermenêutica ao status de filosofia. Uma das suas idiossincrasias consiste em entrelaçar, no seu discurso, experiências de ordem ética, política, metafísica e estética. A hermenêutica filosófica pauta-se pela prática do diálogo sobre questões relativas ao pensar e à conduta humana. O presente artigo tem por meta realizar um exercício dialógico entre o projeto filosófico de Gadamer e o pensamento oriental - mais especificamente, o budismo zen da tradição da escola de Kyoto, representada pelo pensamento de Nishida Kitarō. Nossa reflexão será articulada sobre quatro momentos distintos, mas que devem ser tomados dialeticamente: inicialmente, apresentaremos um quadro geral, indicando o estado da questão da hermenêutica gadameriana relativo ao pensamento oriental; a seguir, sustentaremos as semelhanças sobre o

* $\quad$ Artigo recebido em 25/09/2014 e aprovado em 27/02/2015.

** Prof. Dr. do curso de Graduação e do PPG em Filosofia da Universidade do Vale do Rio dos Sinos UNISINOS. Pesquisador do CNPq. Este artigo contou com apoio do projeto do Edital Universal 14/2012.

*** Doutorando em Filosofia pela Universidade do Vale do Rio dos Sinos - UNISINOS. Bolsista Prosup/Capes. 
modo de proceder de ambas, sua metodologia dialética; posteriormente, aprofundaremos a noção fundamental de experiência e as proximidades que permeiam as perspectivas de ambas as tradições; enfim, como implicação das reflexões precedentes, sustentaremos a hipótese de um saber intuitivo enquanto experiência e ação intuitivas. Ao final, apontaremos algumas conclusões instauradas a partir desse exercício dialógico para a prática filosófica.

Palavras-chave Gadamer, hermenêutica filosófica, experiência intuitiva, Nishida.

ABSTRACT Hans-Georg Gadamer has taken over and raised hermeneutic activity to philosophy status. One of his idiosyncrasies is weaving, in his speech, ethical, political metaphysical and aesthetic experiences. Philosophical hermeneutics is guided by the practice of the dialogue on issues related to thinking and human behavior. This paper aims to perform a dialogic exercise between Gadamer's philosophical project and the Eastern thoughtmore specifically, the Zen Buddhism of Kyoto school tradition, represented by Nishida Kitarō's thought. Our reflection will be divided into four distinct moments that should be taken dialectally: first, we will present a general framework mentioning the status quaestionis of Gadamer's hermeneutics concerning Eastern thought; then, we will maintain the similarities on how the way to proceed in both, its dialectical methodology; subsequently, we will go deeper into the fundamental notion of experience and the proximities that permeate the perspective of both traditions; finally, as implication of foregoing reflections, we will maintain the hypothesis of an intuitive knowledge as intuitive experience and action. In order to conclude, we will consider some conclusions instituted from that dialogical exercise towards philosophical practice.

Keywords Gadamer, Philosophical Hermeneutics, Intuitive Experience, Nishida.

A hermenêutica filosófica gadameriana nutre-se da concepção originária de filosofia que entrelaça experiências de ordem ética, política, metafísica, estética, próprias da tessitura dos textos platônicos. Gadamer sustentou um modo de filosofar tramado pelo espírito dialógico, no qual o que importa mesmo é aprender a dar e a receber argumentos sobre temas que dizem respeito ao 
nosso modo de pensar e de agir. O presente artigo constitui um desdobramento das premissas apontadas, a saber, uma construção argumentativa, uma espécie de aplicação, um diálogo escrito que explicita e aprofunda algumas relações entre o pensamento filosófico e o oriental, que, por sua vez, indicará uma série de corolários positivos e significativos para o exercício filosófico.

Num primeiro momento, como uma espécie de panorama geral, situaremos a problemática da hermenêutica filosófica gadameriana e o pensamento oriental na tradição budista - mais especificamente, o budismo zen da tradição da escola de Kyoto, representada, aqui, pelo pensamento de Nishida Kitarō (1). Num segundo momento, exploraremos a face metodológica que perpassa a hermenêutica e o budismo, quando explicitaremos as proximidades relativas ao modo de proceder de ambas, que são costuradas pelo fio dialético, o que, por sua vez, trama uma metodologia circular virtuosa (2). A seguir, aprofundaremos a noção fundamental de experiência que perpassa o projeto filosófico de ambas as tradições, a experiência hermenêutica, em Gadamer, e a experiência pura, em Nishida (3). Como uma espécie de corolário e ápice das reflexões precedentes, sustentaremos a hipótese de um saber intuitivo enquanto uma experiência e ação intuitivas (4). Ao final, apresentaremos algumas conclusões.

\section{Situação da questão: entrelaçamentos entre a hermenêutica gadameriana e o budismo}

A pesquisa filosófica no mundo indica um crescente interesse em relacionar a filosofia gadameriana com o pensamento oriental, como mostra Palmer (2006), em um artigo que relaciona Gadamer com o Confucionismo. Que a hermenêutica filosófica proposta e difundida por Gadamer, no Ocidente, difere da hermenêutica tradicional que a precede não é novidade. Contudo, do mesmo modo que Gadamer propõe a passagem da hermenêutica exegética, de matiz técnico, à hermenêutica filosófica, que enfatiza o processo de compreensão e sua implicação disso no sujeito que compreende - isto é, o elemento da facticidade, do Dasein humano herdado da filosofia heideggeriana -, no Oriente, mais especificamente no Japão, a escola de Kyoto propõe uma passagem da hermenêutica budista a um modo de proceder filosófico que integra o pensamento de viés teológico, budista, à conceitualização desses preceitos.

Uma das tônicas da proposta gadameriana é a iluminação de si - uma espécie de Selbstaufklärung -, no sentido de compreensão de si mesmo e das limitações inerentes à finitude, à historicidade de cada um, e uma das principais 
tarefas do budismo, independentemente da raiz - indiana, chinesa, japonesa -, é a busca da iluminação imanente, do pensamento autônomo, mesmo que à luz de um princípio transcendente de absoluto. Um dos pontos que une ambas as tradições - hermenêutica filosófica e budismo - é sua base metafísica, que, por vezes, soa vago, irracional, com tom meditativo e intuitivo. Outro aspecto unificante dos dois discursos é a quebra do princípio de identidade de matiz aristotélico, por meio da herança platônica dialógica presente na hermenêutica gadameriana e reforçada pela linguagem budista, tecida com alegorias, aforismos e na ênfase da sabedoria não conceitual em detrimento de uma consciência dualista conceitual (Cf. Thurman, 1978, p. 34).

Palmer (1999, pp. 8-9) afirma que a hermenêutica filosófica de Gadamer é uma defesa sistemática das humanidades e a relaciona com as quatro nobres verdades budistas, a saber: (a1) a vida é sofrimento [descrição do problema]; (b1) o sofrimento é causado pelo apego demasiado [causa do problema]; (c1) a liberação/extinção de desejos é possível [solução ao problema]; e (d1) o caminho das oito vias é o modo para proceder. Na hermenêutica gadameriana, o correspondente seria: (a2) as artes, a literatura, a religião, a filosofia e a poesia não são mais valorizadas; (b2) tais áreas não são mais vistas como 'verdade', uma vez que a perspectiva cientificista definiu verdade como o que é cientificamente verificável; (c2) é possível uma transformação de nossa compreensão de verdade por meio da percepção da verdade em nossa experiência estética; (d2) o caminho das oito vias inicia-se com a 'compreensão plena', assim como a transformação da compreensão de verdade provocada pela experiência estética, seguida de uma adequação ao discurso e à ação, de modo que a aplicação da hermenêutica é explorada, compreendendose historicamente, e, de acordo com a oitava via, alcança-se a verdadeira contemplação, em que a mente não distingue binariamente, entre sujeito e objeto - o que lembra a fusão de horizontes [Horizontsverschmelzung] de Gadamer (1990, p. 311).

Ainda sobre a superação da supremacia do sujeito em relação ao objeto, Byle (2010) compara a solução de Gadamer à de Nāgārjuna, que contorna o objetivismo e o relativismo com base na composição histórico-efeitual e na possibilidade de uma interpretação sempre aberta da realidade. Em outro artigo, Lin (2010) trata da relação entre a verdade ontológica e a verdade proposicional, tratando da problemática instituída por Verdade e Método e seu diálogo com o Samdhinirmocana Sūtra, escritura sagrada cara à escola budista dos Yogācāra, de origem indiana - e à tradição Mahāyāna do budismo -, que visa à transformação da consciência por meio da prática espiritual. Dentro da temática do diálogo e do discurso ontológico e de sua verdade, Johnson 
(2014) relaciona a ontologia de Nishida com a verdade dialógica de Gadamer, ressaltando o pertencimento e a participação do sujeito com a verdade que se manifesta pelo medium da linguagem, de modo que a percepção subjetiva da verdade e do mundo harmonizem-se e correlacionem-se.

No Brasil, os estudos acadêmicos com relação ao pensamento oriental e, em especial, ao budismo, avançam lentamente, com um reconhecimento que se fortalece aos poucos - especialmente pelo grupo de São Paulo, que se dedica a colocar a filosofia em diálogo com o budismo, e, de modo mais direto, com o pensamento zen-budista da escola de Kyoto. Outro grupo de pesquisa sobre o tema é liderado pelo professor Leonardo A. Vieira, da UFMG, cujos resultados das pesquisas estão vindo a público no momento. Entretanto, tais perspectivas não contemplam, segundo nosso conhecimento, a contribuição e a relação do zen-budismo dos pensadores de Kyoto - especificamente, o de Kitarō Nishida - com a hermenêutica filosófica de Gadamer. Ora, isso é o que constitui justamente nosso objeto de reflexão e nossa contribuição.

Com relação à tradição de Heidegger (1982), desde $o$ diálogo sobre $a$ linguagem com um japonês, e por causa do interesse mundial e dos estudos in loco de pensadores japoneses a partir da década de 1930, é fácil perceber a ponte dialógica e filosófica que daí se desprende. Dito isso, nossa proposta parte do pressuposto de que há diferenças naquilo que Heidegger chama de analítica do Dasein e a hermenêutica filosófica propriamente gadameriana - seja com relação ao modo de lidar com a linguagem, com a tradição ou com o aspecto prático da filosofia (Cf. Rohden, 2012a). Em segundo lugar, há pouquíssimas pesquisas dedicadas ao budismo e à escola de Kyoto na tradição gadameriana brasileira, de modo que nossa proposta atende à necessidade de um diálogo que julgamos imensamente profícuo entre a filosofia de Gadamer e o budismo. Em terceiro lugar, a proposta da hermenêutica filosófica é similar, em muitos aspectos, ao que indicam a teoria e a prática budista, seja por seus princípios, seja pela visão de tarefa existencial que ambas as tradições transparecem, seja pelo modo de proceder, isto é, de compreender e de explicar a realidade.

\section{Proximidades entre a metodologia dialética de Gadamer e a de Nishida: configuração da circularidade hermenêutica!}

Em Gadamer, o termo método já não é mais compreendido meramente como um meio para determinado fim, de modo que se conforme a verdade a uma certeza. A metodologia desenvolvida por Gadamer, própria hermenêutica filosófica, desenvolve-se sob a forma de uma dialética-dialógica, um jogo circular, uma troca virtuosa, que torna o sujeito consciente e capaz 
de compreender suas idiossincrasias e suas implicações no processo da compreensão e da instauração de sentido. A noção de círculo hermenêutico é tomada de Heidegger, e explicita o elemento da historicidade e das marcas preconceituais do sujeito - da sua compreensão repleta de preconceitos/juizos sem fundamento [Vorurteile] (Gadamer, 1990, p. 275) - que estão presentes no processo hermenêutico. Assim, quem filosofa hermeneuticamente está aberto à alteridade de outrem, à verdade alheia. Dar-se conta das próprias condições de verdade, das limitações e da finitude faz parte do processo dialético-dialógico, que se fundamenta em uma proposta de alteridade e consideração da verdade do outro.

Sócrates, na Apologia (21 d), também afirma que nada sabe, nada conhece, enfatizando a finitude, a incapacidade de conceitualizar a realidade e dizê-la, em paralelo aos ensinamentos budistas e à proposta de Nishida. Gadamer, por sua vez, resgata a dimensão do diálogo socrático, de modo que a verdade não está no sujeito, tampouco no objeto - pois não há prevalência de um em relação ao outro -, mas na experiência, no jogo de sujeito e objeto, na troca experiencial que se efetiva via argumentação. De outra parte, uma das principais propostas de Nishida tem a ver com sua tentativa de superar o dualismo sujeito-objeto na linguagem experiencial. Porém, não devemos perder de vista o pano de fundo fenomenológico husserliano e bergsoniano por trás dessas propostas, que se alinham em horizontes similares ao tratarem da percepção intuitiva como um momento de compreensão que não se resume à ação em direção ao objeto, mas muito mais à recepção deste, pelo fato de estar aberto à experiência hermenêutica.

Nishida foi influenciado pela hermenêutica diltheyana, de modo que seu pensamento tardio tem sua ênfase não tanto na metafísica e na epistemologia, mas na história e na sociedade. Percebe-se a face da historicidade [Geschichtlichkeit] presente ao ressaltar a necessidade de se constituir a consciência da realidade a partir da experiência de compreensão de mundo como simultaneidades de um eterno presente - similar ao que propõem Nietzsche e Kierkegaard, por exemplo -, em que o mundo histórico se explicita como uma identidade de contraditórios - ou seja, que leva em consideração as incongruências e o caráter contingencial da vida humana. A temporalidade e a existência humana são pensadas a partir de uma noção de presentificação, que pode ser compreendida do ponto de vista da finitude; desse modo, o fluxo temporal do futuro e o do passado encontram-se e harmonizam-se em um círculo infinito (Cf. Yoshinori, 2004, p. 198), e, assim, voltamos, pois, à noção de circularidade proposta pela hermenêutica gadameriana. 
A perspectiva do diálogo como fio condutor da hermenêutica baseia-se na dimensão da relação ética e de alteridade com relação à verdade de outrem. Desse modo, é bastante clara a relação de Gadamer com Nishida (1970, p. 64), quando afirma que "a relação Eu e Tu é unida através da expressão. [...]. A existência do $\mathrm{Tu}$ é apenas a firme convicção do Eu. Mas, sem o Tu, o eu não tem sentido". Em Hermenêutica enquanto filosofia prática, Gadamer afirma que "o conhecimento teórico sobre a experiência da compreensão e a práxis da compreensão - isto é, a filosofia hermenêutica e sua própria autocompreensão - não podem ser separados" (Gadamer, 1998, p. 112). Por esse motivo, o exercício hermenêutico filosófico proposto por Gadamer está enraizado, enquanto teoria e prática, na vida ética (Schmidt, 2012, p. 36). A hermenêutica filosófica é concebida como uma arte de compreender o mundo na qual o próprio ser que compreende, compreende-se. Trata-se de uma prática de compreensão de si [Selbstverständnis] ou conhecimento de si mesmo -

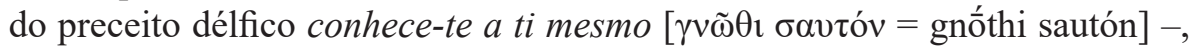
como na tradição socrático-platônica - também tratada por Foucault (2001) e

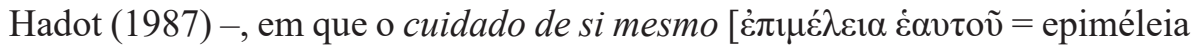
heautoû], expresso no Alcibíades I, de Platão, é ressaltado como uma forma de exercício espiritual, de interiorização e introspecção com a alma, que define a proposta inicial da filosofia, que se define como uma forma de escolha de vida, de guia existencial.

A hermenêutica gadameriana, elevada ao status de filosófica, conservou e superou a hermenêutica precedente, que se configurava como metodológica enquanto uma espécie de exegese textual e técnica/teoria da boa interpretação, que desconsidera os aspectos históricos, políticos, existenciais nesta tarefa. "Contudo, compreender com sentido significa assumir e tecer uma relação dialética, tensional, que gera uma terceira margem emergente do interpretar. Com isto, podemos superar a lógica da identidade ou do Tertium non Datur" (Rohden, 2003, p. 111), isto é, o método dialético-dialógico proporciona uma solução para a dicotomia binária. Nishida também propõe sua filosofia baseada na dialética, de modo que "a verdadeira autoidentidade não toma a forma de 'A é A', mas de uma unidade de contraditórios", de modo que não se trata de uma negação do princípio de não contradição, mas uma relativização deste, pois "Nishida não diz 'A é não A', mas, sim, algo como 'A em não A é A"” (Heisig, 2001, p. 65).

Aliás, é tácito, na tradição budista, compreender a realidade como lugar de dualidades que não têm pretensão de serem sintetizadas, simplificadas, mas que permanecem contraditórias, como no kōan: "uma montanha é uma montanha, uma montanha não é uma montanha, uma montanha é e não é uma 
montanha". ${ }^{1}$ Do ponto de vista gadameriano, assume-se o filosofar como um exercício no qual o nosso lógos é limitado e incapaz de esgotar ou dizer o real tal qual ele realmente é, ou seja, sempre fica algo de não dito no dito. Além disso, toda determinação é uma negação do que aquilo não é. Em outras palavras: ao afirmar 'A é belo', a tendência é inferir que 'Não A é feio' e/ ou que 'A é não feio'. Com a perspectiva dialético-dialógica mantida tanto por Gadamer quanto por Nishida - um pelo matiz platônico, outro pela tradição zen-budista -, rompe-se a noção da oposicionalidade, de modo que se preserva $o$ não dito de algo em sua integralidade, e mesmo $o$ dito não se torna algo determinante e absoluto, com pretensão absolutizadora e dominadora do objeto. Tratar da compreensão como algo que perpassa a linguagem e faz uso desta para dizer o real de forma dialética e dialógica é perceber o que o outro tem a dizer sobre as coisas, encarando as inúmeras interpretações de mundo, as concomitâncias de sentido - isto é, os múltiplos sentidos, ao mesmo tempo, sobre o mesmo objeto -, o também, o imediato e o assim como do real. O próprio discurso teológico de Nishida compreende Deus de forma dual, uma vez que, "para Nishida, Deus é deus absconditus e deus revelatus ao mesmo tempo. Aqui está a mesma relação dialética obtida entre eternidade e presente" (Yoshinori, 2004, p. 199).

Tanto em Nishida quanto em Gadamer, há uma necessidade de manter a oposicionalidade, o que corresponde a aprofundar-se no contraditório. A unidade encontra-se justamente no quanto mais permitimos a oposicionalidade, a contraditoriedade, pois se a realidade é contraditória, como afirmara Hegel, quanto mais contraditoriedades forem mantidas, sem a necessidade de uma síntese ou um consenso específico, mais verdadeira será essa realidade.

Como princípio ético, Gadamer também propõe a não necessidade de ter certeza ou a possibilidade de que o outro [também] pode ter razão, o que não significa relativismo, mas uma forma de conceber a verdade e o discurso filosófico dentro de um matiz consciente de sua finitude, sua limitação linguística, sem reduzir o outro ao eu. Na visão de Nishida, ao vermos contraditórios e contrários "coincidindo no mundo do ser, vemos como consciência e linguagem têm problemas em colocar-se com os fatos naturais da experiência como se apresentam a nós, e, ao mesmo tempo, os vemos como um microcosmo da dialética definitiva de ser e nada" (Heisig, 2001, pp. 67-68).

1 Agradecemos, aqui, ao Prof. Dr. Peter Phan (Georgetown University), que, em conversa conosco, em 2012, usou esse exemplo budista para explicitar a superação do dualismo do lógos grego em relação à expressão oriental proveniente do budismo. 
Uma das implicações do processo hermenêutico filosófico diz respeito à transformação do modo de ser de quem se propõe a compreender. Ela instaura, pois, um movimento de mudança de visão de mundo em direção ao mais universal. $\mathrm{O}$ aspecto prático da hermenêutica filosófica funda-se na qualificação existencial e espiritual do ser humano. Ao ligar a hermenêutica à noção kantiana, Schmidt (2011, p. 52) afirma que "o prazer que percebemos nessa Lebensgefühl [sensação de vida] cruza as distâncias entre o si mesmo e o mundo [...] e transforma [o modo] como somos no mundo". Dessa maneira, o movimento da vida traduzido pelo exercício hermenêutico é enfatizado na transformação de si mesmo, isto é, como o processo de alargar e fazer convergir horizontes que nos torna mais unos e plenos.

$\mathrm{Na}$ hermenêutica, a compreensão interpretativa não é meramente teórica, mas ligada à prática do ser humano. Ela, portanto, "forja o centro, o 'quem' que nos tornamos; torna-se a base de como viemos a saber e conceitualmente articular nosso mundo e nós mesmos” (Schmidt, 2012, p. 42). A hermenêutica pode ser compreendida como uma caminhada circular, pois parte da compreensão do mundo em direção e a partir da vida fática. Gadamer

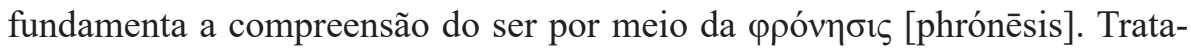
se de um saber que não é técnico, apreensível e ensinável conceitualmente, pois não se trata de um conhecimento objetivo, meramente conceitual e

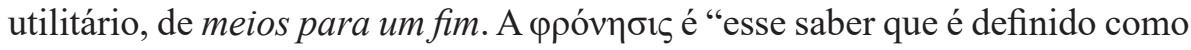
orientação, comportamento e caráter que nos leva às nossas vidas fáticas" (Schmidt, 2012, p. 44). Enquanto prudentia, esse exercício filosófico nos forma, nos caracteriza enquanto seres humanos capazes de viver eticamente, definindo-nos como tais.

Na Carta Sétima, Platão descreve a dialética em seus movimentos ascendente e descendente, isto é, da palavra ao conceito e o caminho de volta, do conceito à palavra. A proposta hermenêutica de Gadamer está relacionada ao aspecto descendente da dialética de Platão, pois "o diálogo hermenêutico, enquanto modelo estrutural tanto de compreensão quanto de 'correção' do real, implica também a efetivação da justiça e da liberdade" (Rohden, 2012b, p. 109). A volta à Caverna é o processo descendente da dialética, que se restringe ao caráter ético e político da hermenêutica e da filosofia, de modo que "compreender não é, em todo caso, estar de acordo com o que ou quem se compreende. [...]. Compreender significa que eu posso pensar e ponderar o que o outro pensa" (Gadamer, 2000, p. 23). Ainda na Carta Sétima (341 c-d), Platão afirma que há matérias [ $\mu \alpha \theta \eta ́ \mu \alpha \tau \alpha=$ mathếmata] sobre as quais ele não escreveria em tratados [ $\sigma u ́ \gamma \gamma \rho \alpha \mu \mu \alpha=$ sýngramma], tampouco poderiam

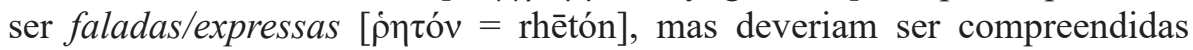




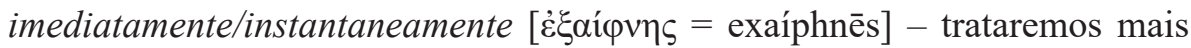
da compreensão imediata na quarta sessão, na qual exploraremos o conceito de intuição ativa de Nishida e nossa perspectiva de experiência intuitiva a partir de Gadamer. Como se vê, a proposta metodológica de ambos é fundamentalmente dialético-dialógica e ancora-se na perspectiva de que o que importa mesmo é o exercício de compreensão e explicitação do real do qual somos partícipes.

\section{Fios que perpassam a experiência hermenêutica em Gadamer e a experiência pura em Nishida}

A experiência que alguém faz transforma o conjunto do seu saber. (Gadamer, 1990, p. 359)

Do conceito e da explicitação anterior ao que concerne o círculo hermenêutico, que supera a dicotomia sujeito-objeto, que coloca em xeque a historicidade e a participação dos preconceitos na compreensão do ser humano, passamos a um dos propósitos da filosofia de Gadamer e de Nishida, a saber, o da experiência. $\mathrm{O}$ exercício dialético não visa apenas à elaboração de um conceito vazio e abstrato, mas almeja, em última instância, a realização de uma experiência filosófica. Mostraremos como os dois projetos - de Gadamer e de Nishida - entram em consenso, apontando a experiência do sujeito, como o ápice da compreensão, que se realiza e se atualiza na experiência de instaurar sentido do sujeito, em uma ação que não é meramente racional e/ou passional, mas, antes, intuitiva. Para tanto, retomaremos reflexões realizadas acerca da noção de experiência a partir da Carta Sétima de Platão, em que o indizível, a coisa mesma, não se diz de forma conceitual-abstrata, neutra, mas afeta e transforma o sujeito que a realiza.

$\mathrm{Na}$ proposta hermenêutica, a verdade a ser inquirida tem fator de algo a ser revelado, desvelado, desocultado, como característica tácita à $\dot{\alpha} \lambda \hat{\eta} \theta \varepsilon 1 \alpha$ [alếtheia], herança heideggeriana - isto é, o que não pode ser esquecido, passar despercebido, no sentido de $\lambda \hat{\theta} \theta \omega / \lambda \alpha v \theta \alpha ́ v \omega$ [lêthō/lanthánō]. Contra as pretensões, a hegemonia da experiência cientificista - equivalente à noção de experimentação/experimento - e o primado da $\tau \dot{\varepsilon} \chi v \eta$ [téchnē], Gadamer propõe a retomada da tradição humanista. Esta é uma das razões pelas quais a primeira parte de Verdade é Método é dedicada à experiência estética do belo

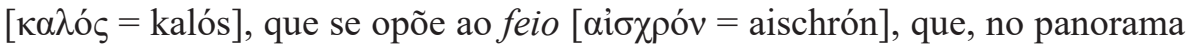
grego herdado por Gadamer, respectivamente, é algo que se mostra, à luz, em relação a algo que se oculta, se esconde na escuridão. 
Mas que caminho é este que não o da experiência? A experiência hermenêutica é, antes, uma experiência dialética negativa, pois o objeto com o qual se experiencia deve ser passível de propiciar um saber melhor, em uma espécie de troca dialética, com uma negação determinada (Cf. Gadamer, 1990, pp. 358-359). A noção de experiência sustentada por Gadamer deita raízes no termo Erfahrung, da Fenomenologia do Espírito de Hegel. Segundo a formulação hegeliana, "o movimento dialético que realiza a consciência consigo mesma, tanto em seu saber como em seu objeto, à medida que para ela o novo objeto verdadeiro surge precisamente daí, é na realidade o que chamamos experiência" (Hegel in Gadamer, 1990, p. 360). Contudo, enquanto que, para Hegel - segundo interpretações usuais -, a consciência realiza tais experiências para certificar-se da certeza de si mesmo, como um modo de ciência da experiência da consciência - como deveria ter se chamado inicialmente a obra (Cf. Stern, 2001, p. 8) -, com uma extensa explicação do termo ainda na introdução de Fenomenologia do Espírito (Cf. Rockmore, 1997, p. 32), Gadamer reconhece a experiência como possibilidade de transformação do ser humano, do Dasein, de modo que a experiência não se resume a uma inversão da consciência, pois há o retorno a si mesmo e ao outro. A experiência gadameriana não se resume ao retorno ao espírito absoluto, mas compreende as noções de espírito [Geist]

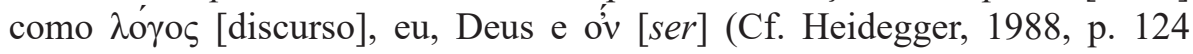
ss.). Trata-se de uma experiência existencial, histórico-efeitual e de finitude, por meio da qual o ser humano compreende a si mesmo e à sua realidade circundante em uma espécie de meditação, de exercício espiritual, ao modo de uma adequação memorial interiorizante [Erinnerung], um movimento dialético de consciência de si que se abre ao outro. O movimento dialético é, de certa forma, um modo de autocompreender-se e autorreconhecer-se, pois "a dialética do reconhecimento é experiência em progresso" (Gadamer, 1976, p. 76).

Na proposta de Nishida Kitarō, a compreensão é instituída por meio de uma experiência pura [junsui heiken], uma experiência que não é mediada pela linguagem escrita, por conhecimentos prévios, pois "se trata de um 'não conhecimento' anterior à discriminação e ao discernimento. A 'experiência pura' é uma experiência anterior ao conhecimento que se desdobra em direção ao conhecimento a partir do "não conhecimento"' (Ryōsuke, 2014, p. 297). A experiência, nessa perspectiva, consiste em procurar ver as coisas tais como são, isto é, com um matiz profundamente fenomenológico. Ora, aqui encontramos semelhanças com a perspectiva de Gadamer marcada pela noção de fenomenologia de Husserl e de Heidegger. A experiência pura é uma 
experiência que Nishida caracteriza como uma experiência desprovida de discriminação deliberativa, uma forma de recepção dialética sem formação de juízos. Trata-se de uma experiência imediata e não mediada, uma forma de recepção intuitiva que busca conhecer os fatos tais como eles são. A experiência pura assemelha-se, ao final de seu processo, àquilo que Gadamer concebe como fusão de horizontes, no sentido de plenificação do que Platão chamou de Bem. Ora, "a experiência pura inicia o processo dinâmico da realidade que diferencia em fenômenos subjetivos e objetivos a caminho de uma unidade superior, e a recaptura de nosso fundamento unitário é o que Nishida quer dizer com Bem" (Maraldo, 2012).

A experiência pura acontece "quando alguém diretamente experiencia seu próprio estado de consciência”, ou seja, quando "ainda não há um sujeito ou um objeto, e o conhecimento e seu objeto estão completamente unificados. Esse é o tipo mais refinado de experiência" (Nishida, 1990, pp. 3-4). Em outras palavras, "a experiência pura é a intuição de fatos tal como eles são e é desprovida de significado" (Nishida, 1990, p. 8). Para Nishida (1966), tudo

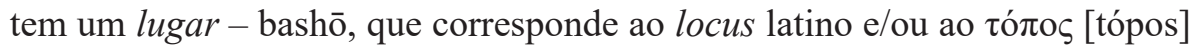
grego -, de modo que há um mundo da natureza (realidade), um mundo da experiência interior (consciência) e um mundo da inteligibilidade (ideias). A concepção do autor é que "tudo que é, é em outra coisa. Se não fosse assim, não haveria modo de distinguir entre o que é e o que não é" (Nishida in Heisig; Kasulis; Maraldo, 2011, p. 649) - por isso mesmo que o lugar da consciência mais profunda é o nada, no qual a consciência e a vontade são verdadeiramente livres. O lugar de Nishida compreende as dimensões subjetiva e objetiva

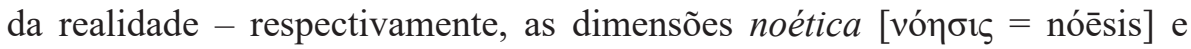
noemática [vó $\mu \alpha=$ nóēma]. O lugar a que Nishida se refere também pode ser compreendido como horizonte, e, hermeneuticamente, como o lugar para o qual os horizontes convergem. A convergência de horizontes ou fusão de

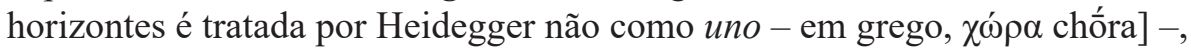
mas como um ponto de convergência. Desse modo, a facticidade [Faktizität] é relacionada à noção de linguagem como o medium do ser humano, o local onde o ser ocorre (Shields, 2011, p. 142).

A noção de pura experiência defendida por Nishida tem relação com um exercício de pura consciência, de modo que há determinada equivalência à ideia de universalidade da experiência de Hegel, que, na hermenêtica filosófica de Gadamer, é retomada por meio da experiência da obra de arte, do jogo, do círculo hermenêutico. A pura consciência é um exercício interior do despertar budista, que corresponde, em parte, ao esclarecimento [Erklärung] do idealismo alemão, mas sem a perspectiva meramente racional, mas intuitiva. 
Há paralelos, pois, entre a experiência pura e a hermenêutica na medida em que ambas pretendem despertar o sujeito para seu lugar no mundo, suas condições existenciais, fáticas etc. Realizar uma experiência hermenêutica significa estar disposto a ser afetado por ela, abrindo-se à experiência transcendental e, de certa forma, à noção de $\mu \varepsilon \tau$ óvoı $\alpha$ [metánoia] grega - tema abordado especificamente por Tanabe Hajime (1986), em Filosofia como Metanoética -, isto é, trata-se de fazer a experiência filosófica par excellence.

Fazer o percurso teórico-prático da tarefa filosófica é descrito por Gadamer (1990), em diversos momentos, como um exercício de romper com os preconceitos [Vorurteile], dar-se conta das limitações e dos condicionamentos históricos que nos afetam e que estão presentes em nosso modo de compreender. Shields (2011, p. 143), ao comparar o budismo crítico com a hermenêutica filosófica, ressalta a ligação de Wirkungsgeschichte (história efeitual) com o conceito budista de upāya (caminho da aprendizagem). Tanto o budismo - e a proposta filosófica baseada nessa tradição, como a de Nishida e da escola de Kyoto como um todo - quanto a hermenêutica filosófica implicam uma postura - a Tugend gadameriana - em relação ao mundo e à vida a partir da transformação de si mesmo. Não se trata, pois, de um exercício estritamente lógico, dedutivo, cognitivo, mas dialético, dialógico, intuitivo e prático.

A verdade que tanto a experiência hermenêutica quanto a experiência pura buscam não se relaciona com a verdade enquanto veracidade científica e/ou experimento comprovável, verdade verificável, empírica. A rigidez conceitual não descreve a experiência filosófica defendida tanto na perspectiva gadameriana quanto na oriental de Nishida, pois "o engodo da conceituação - sua pretensão de universalidade acima de tudo, mas também a noção de que no conceito algo é condensado e dito - inegavelmente configurou a filosofia e sua noção do que se qualifica enquanto verdade" (Schmidt, 2011, p. 48). A verdade proposta pela experiência hermenêutica e a experiência pura é uma verdade idiomática (Cf. Schmidt, 2011), isto é, não tem pretensão conceitual desvencilhada do real. Trata-se de uma experiência que retrata o Lebensgefühl de matiz kantiano, como afirma Schmidt (2011), isto é, um sentimento de vida, uma percepção do movimento vital, que proporciona uma transformação de nós mesmos.

A experiência hermenêutica de Gadamer compõe-se de pelo menos três momentos, na perspectiva de Verdade e Método: (a) por meio da experiência estética; (b) do círculo hermenêutico; e (c) da linguagem. A proposta de Nishida também engloba esses três aspectos, inclusive com um livro em que relaciona a moralidade à arte, de modo que há uma tentativa de formular um lugar-comum para as noções de arte e moralidade, pois compreende e 
propõe que a arte possui um eterno agora ou uma eterna presentificação, pois sempre se atualiza, na medida em que perpassa tempo e espaço. Similar à perspectiva grega, Nishida "estava comprometido a uma correlação de verdade, bem e belo, e realizou tal comprometimento ao tentar ver arte e moralidade enquanto expressões de si da mesma força vital operando nos fundamentos da consciência - vontade absoluta" (Heisig, 2001, p. 57). Gadamer parte do ponto de vista ocidental de arte, enquanto que Nishida aborda, além desses artistas, os do Oriente, que se destacam por sua não limitação e por seu não enquadramento, sem a ideia de Bild, de cĩ $\delta$ os [eîdos]. Essa experiência de tomada de consciência de Nishida pode ser compreendida como uma plenificação do Dasein, uma transformação de si, pois o momento de percepção e identificação de si mesmo na obra de arte é um momento de transformação de si, no momento em que se compreende a moralidade não em seu perfil universalizável - tal como na tradição kantiana -, mas a partir da percepção do impulso da vida, da vontade (Cf. Schmidt, 2013).

A experiência, nesse sentido, não visa apenas conhecer o real, mas saboreá-lo internamente, isto é, instaurar sentido e transformar nossa forma de viver, nosso modo de ser no mundo, aliando a compreensão e o conhecimento com o cuidado de si mesmo proposto pelo oráculo de Delfos e difundido por Foucault (2001) e Hadot (1987). Em um panorama budista, a experiência apresenta-se como uma forma de traduzir o caminho em busca de sabedoria e iluminação de si mesmo, em busca de uma ascensão de si mesmo. Implicitamente, tal como Gadamer estava preocupado com as condições de racionalidade desenvolvidas ao longo do século XX e a tarefa de repensar o papel imprescindível das ciências humanas, Nishida passa por um momento de repolitização e crítica radical do modo como se fundamentava a filosofia japonesa até então, propondo teorias com matiz ético.

Em terras brasileiras, com sentido universal, Guimarães Rosa tematizou, com outras palavras, a noção de experiência nos moldes propostos por Gadamer e Nishida, no termo travessia, como lemos no Grande Sertão: Veredas. Para Riobaldo, em seu 'range rede', interessou mostrar que a vida instaura-se através do tempo, ela é em seu vir-a-ser, o que se corporifica na última palavra do mencionado romance, ou seja, travessia. De acordo com Martins (2008, p. 501), no romance em questão, o termo tem um "sentido simbólico de vida, transposição de etapas". A experiência filosófica realizada por Riobaldo consistiu em recriar "as situações e, ao recriá-las, elas ganham forma diversa da que realmente aconteceu [...]. A vida narrada não é a que ele viveu, mas a que é filtrada pela memória, é a que ganha forma pela linguagem 
dele, enquanto ele conta. Quando ele acaba de contar, ela é só 'travessia"' (Barros, 2014, p. 90).

\section{0 saber intuitivo enquanto experiência e ação intuitivas}

[...] e a gente tem de necessitar de aumentar a cabeça, para o total. (Guimarães Rosa)

A interpretação gadameriana conta com o mote grego - mormente platônico-aristotélico -, de modo que a compreensão hermenêutica está diretamente ligada ao que Platão descreve, no excursus da Carta Sétima, isto é, os modos de dizer/compreender as coisas, que são quatro momentos que se complementam e se completam no movimento dialético: nome [ő้ $\mu \alpha \alpha=$

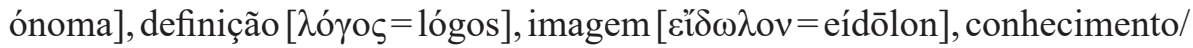

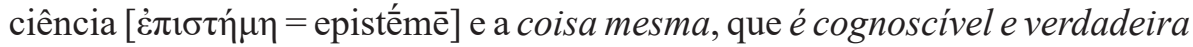

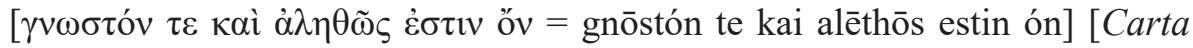
VII, 342 a-b], ou como afirma Gadamer, a coisa mesma [die Sache Selbst] (Gadamer, 1980, p. 100). Na perspectiva de Nishida, a compreensão mais completa e profunda do real efetiva-se mediante um processo de percepção intuitiva - no sentido de voũ [noûs] -, isto é, que não se fundamenta tão somente na razão. Intuição significa ver algo de modo imediato, perceber algo sem precedentes racionais de [re]conhecimento, "é o conhecimento direto da verdade ou do todo da coisa em questão" (Yoshinori, 2004, p. 206). Trata-se de um tipo de ação-intuição (kōi-teki chokkan), que pode ser compreendida como uma ação receptiva das coisas no mundo (Cf. Maraldo, 2012).

Um novo paralelo entre Gadamer e Nishida, quanto à intuição, pode ser apreendido na célebre afirmação gadameriana, de que ser que pode ser compreendido é linguagem, ou seja, as coisas mesmas podem ser experienciadas pela consciência. Enquanto Gadamer retoma e concebe a linguagem como um medium que possibilita o sujeito compreender de modo mais apropriado o real e de expressar a verdade, Nishida defende a necessidade de purificar a consciência do sujeito para torná-lo capaz de ver diretamente, acessar imediatamente, a coisa mesma. De acordo com Heisig (2001, p. 44), “o termo 'visão direta', na verdade, é maneira japonesa mais simples de traduzir Anschauung ou intuição", que é uma forma de insight da coisa mesma, que corresponde ao quinto momento descrito acima na Carta Sétima.

A experiência da consciência de Nishida é sempre uma experiência de autoconsciência ou consciência de si mesmo - tal como na proposta 
de experiência hermenêutica, em que há a compreensão de si mesmo e o respectivo impacto em si mesmo para que haja uma transformação do ser-nomundo [In-der-Welt-Sein] -, que carece de julgamento, pensamento racional e intencionalidade, superando a relação de sujeito e objeto, constituindo-se como o que o autor chama de pensamento puro. Nas palavras de Nishida (1990, p. 30), "a intuição intelectual (intellektuelle Anschauung) é uma intuição de coisas ideais e usualmente transexperienciais. Ela intui aquilo que pode ser conhecido dialeticamente", e tal experiência corporifica-se na expressão livre da vontade do artista, em sua obra de arte, por exemplo, ou na experiência religiosa.

A experiência intuitiva da consciência é uma experiência hermenêutica de conhecimento e cuidado de si; trata-se de uma forma de despertar a si mesmo, tornar-se [verdadeiramente] consciente. Tal forma de acesso intuitivo à verdade não é uma espera que as coisas sejam percebidas, mas um ponto de vista, um tipo de ascese espiritual em direção à coisa mesma; é algo ativo, não simplesmente passivo. Enquanto que a ação parte de nós mesmos (do eu) ao mundo, a intuição parte do mundo a nós mesmos (de volta ao eu). Há uma troca, em uma espécie de jogo entre sujeito e objeto, entre si mesmo e o mundo, de modo que o sujeito deve se reconhecer como parte do mundo, como parte desse processo dialético. Há uma relação de reciprocidade ou de diálogo entre o si mesmo - nossa identidade, o reconhecimento de si mesmo, o eu/ego - com o mundo, de modo que interajam entre si. Entretanto, "a autoconsciência, no sentido de uma consciência da verdadeira identidade da pessoa individual, não pode ser disposta em uma simples oposição a outras pessoas, uma vez que isso reintroduziria a dicotomia sujeito-objeto pela porta de trás" (Heisig, 2001, p. 79).

"O eu deve ser entendido como um sujeito que não é um não objeto, e o mundo deve ser entendido como um objeto que não é um não sujeito. Como afirma Nishida, é preciso despertar a "um ver sem um vidente"' (Heisig, 2001, p. 55). Tal como na experiência hermenêutica há uma forma de experiência de totalidade, na concepção de Nishida, sua intuição ativa proporciona um conhecer tornando-se o que se conhece, o que, metaforicamente e em linguagem budista, significa a transformação do eu no processo intuitivo. Assim como Platão trata das coisas sobre as quais não há linguagem adequada para dizê-las, Gadamer trata da experiência como uma forma de acesso à verdade que não é dizivel totalmente, mas pessoal, unitária e intransferível. Para Nishida, “tal 'conhecimento' não é suscetível à expressão em termos objetivos ou subjetivos" e "sua expressão não objetiva substituir nem simplesmente suplementar a linguagem de sujeitos e objetos, mas exprimir 
uma consciência das limitações de tudo que podemos compreender e dizer por conta da dicotomia que realizamos entre o eu e o mundo" (Heisig, 2001, p. 56).

Nishida trata do conceito de despertar de si/autodespertar (jikaku) (Maraldo, 2012), no sentido de que "a autoconsciência do si mesmo, conforme expressa na filosofia de Nishida, é sempre um autodespertar em meio à experiência direta do 'lugar', e o caráter factual da própria vida" (Ryōsuke, 2014, p. 310). O lugar ideal, como já ressaltamos, é o nada absoluto (zettai$m u$ ), que é uma forma de negação originária que precede o pensamento, e é com esse conceito que "Nishida quer ultrapassar a dialética hegeliana e a metafísica ocidental em direção a uma dimensão mais profunda, anterior à ontologia do ser e ao princípio da subjetividade moderna" (Müller, 2013, p. 27) - principalmente uma crítica ao cogito cartesiano e do solipsismo racionalista e ao eu transcendental kantiano, além do princípio de autonomia do puro pensar hegeliano.

Contudo, o nada de Nishida não corresponde diretamente ao não ser ocidental, de matiz grego e compreendido quase exclusivamente como oposto/ negação do ser. Em parte, tal limitação interpretativa é fundada por conta de uma interpretação limitada do Sofista (250 a), de Platão, que interpreta ao pé

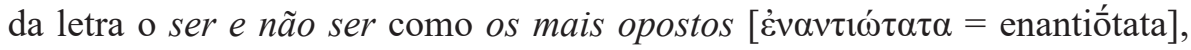
esquecendo-se dos princípios básicos da dialética-dialógica platônica, do artifício platônico de fazer uso da contradição e da contrariedade dependendo do operador lógico -, a fim de explicitar múltiplas possibilidades de determinação em um caráter de finitude, de incompletude e de abertura para novas interpretações e determinações.

Para Nishida, a busca filosófica não envolve apenas autorreflexão

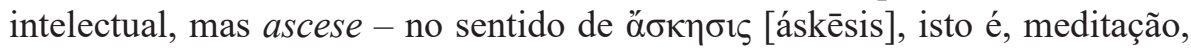
prática - e abnegação, pois somente esvaziando-se é que se consegue ver as coisas ao tornar-se elas (Cf. Davis, 2011, p. 41). Assim como na hermenêutica filosófica gadameriana a experiência é o meio pelo qual se compõe o conhecimento, portanto, de forma não limitada à razão, a ação intuitiva de Nishida propõe algo similar, na medida em que toda compreensão propiciada pela intuição deve ser própria, não apreendida pela tradição, mas vivida, experienciada. Desse modo, o exercício compreensivo é um exercício para ver o real por si próprio, e "tornar-se consciente da realidade é tão diferente de tornar-se um simples eu que pode ser chamado de obra do "não eu", e "enquanto a consciência de si aponta para um campo no qual a realidade é compreendida por um eu individual, o despertar de si aponta para um campo no qual a realidade torna-se ciente de si mesmo no eu individual" (Heisig, 2001, p. 51). 
Nishida sustentou a superação da dicotomia sujeito-objeto promovendo uma conversão de ponto de vista de despertar, que, segundo Heisig (2001, p. 55), é seu modo de definir ser, isto é, por meio da intuição ativa, que muda o modo de ser de quem compreende - conhece-se ao tornar-se um pouco o objeto a ser compreendido, muito similar ao Ser-com [Mit-Sein] heideggeriano, que remete ao conceito de participação [ $\mu \varepsilon \dot{\varepsilon} \varepsilon \xi \xi \varsigma=$ méthexis] platônico, que corresponde à noção de Verstehen, que é o compreender no sentido de estarcom, estar próximo a. Dessa forma, ao experienciar, tornamo-nos mais próximos do que verdadeiramente é, em analogia à metodologia da Carta Sétima de Platão, mais abertos e conscientes de nós mesmos, da realidade, dos outros e do todo, transformando-nos em seres mais virtuosos, vigilantes, despertos.

O pressuposto fundamental da experiência intuitiva é a instauração do sentido que visa, na verdade, à apreensão da totalidade da vida, das coisas, do mundo, ou seja, da coisa mesma. A intuição da totalidade ou da unidade contrapõe-se à lógica binária, dual e sustenta a visão e compreensão complexa, holística e em forma de rede do real. Ora, esse pressuposto metafísico implica e aponta corolários de ordem ética, política. Em outras palavras, a efetivação da experiência intuitiva implica, pois, uma ação do mesmo tamanho, ou seja, totalizante, que nos torna capazes de relativizar mesquinharias, de perdoar, de minimizar agressões, de lidar com posturas totalitárias. O saber, enquanto um experienciar intuitivo, torna-nos mais completos, mais unos, mais livres para com as coisas, com as pessoas, com o mundo, com a história. Não por acaso é que Rosa (2003, p. 90) tenha também tecido seus textos com o primado da intuição, conforme nos diz: 'meus livros são, em essência, 'anti-intelectuais' defendem o altíssimo primado da intuição, da revelação, da inspiração sobre o bruxolear presunçoso da inteligência reflexiva, da razão, a megera cartesiana". O próprio Riobaldo convoca seu leitor a realizar a experiência intuitiva, conforme sua fala, "porque a cabeça da gente é uma só, e as coisas que há e que estão para haver são demais de muitas, muito maiores diferentes, e a gente tem de necessitar de aumentar a cabeça, para o total” (Rosa, 1958, p. 294).

\section{Algumas conclusões}

Concluímos nossa reflexão retomando a seguinte afirmação de Rosa (1958, p. 35): "eu atravesso as coisas - e no meio da travessia não vejo! - só estava era entretido na ideia dos lugares de saída e de chegada". Essa formulação expressa os fios que perpassam a hermenêutica filosófica de Gadamer e a filosofia de Nishida, na medida em que o exercício reflexivo consiste em 
compreender as origens, as causas, "os lugares de saída" nos moldes da noção de $\grave{\alpha} \rho \chi \eta ́$ [archế] grega. Em contrapartida, a atividade do pensamento reside em apreender a causa final, o fim para o qual as coisas foram criadas e em função do qual tudo existe, "os lugares de chegada". Porém, o que importa, para as propostas filosóficas de Gadamer e de Nishida, entre outras coisas, é a instauração do sentido, é o entrelaçamento entre o ponto da saída e o ponto da chegada, é o entrecruzamento, a travessia mesma permanente entre arqueologia e teleologia. Dito de outra maneira, o importante para as filosofias mencionadas é esse exercício de consciência do nosso tempo, é ver, ouvir e saber agir no meio da própria travessia. O itinerário, o caminho deixam de ser vistos como instrumentos e meios para obtenção de um fim externo ao sujeito e tornam-se sua própria razão e o sentido de ser. Eles se convertem em experiência de sentido sob a perspectiva da totalidade. Institui-se, assim, um saber intuitivo no qual "aumentamos nossa cabeça para o total".

\section{Referências}

BARROS, B. M. “A existência ilusória do diabo em Grande Sertão: Veredas: Rastros Budistas Na Obra De João Guimarães Rosa”. Dissertação (Mestrado em Letras) Programa de Pós-Graduação em Letras, Pontifícia Universidade Católica do Rio Grande do Sul, Porto Alegre, 2014.

BYLE, N. "Gadamer and Nagarjuna in play: Providing a new anti-objectivist foundation for Gadamer's interpretive pluralism with Nagarjuna's help". Thesis (Master of Arts - Department of Religious Studies) - University of South Florida, 2010.

DAVIS, B. W. "Dialogue and Appropriation: The Kyoto School as Cross-Cultural Philosophy". In: B. W. Davis; B. Schroeder; J. M. Wirth. Japanese and Continental Philosophy: Conversations with the Kyoto School. Bloomington: Indiana University Press, 2011. p. 33-51.

FOUCAULT, M. "L'herméneutique du Sujet: Cours au Collège de France, 19811982”. Paris: Gallimard; Seuil, 2001. (Hautes Études).

GADAMER, H. G. "Hegel's Dialectic: Five Hermeneutical Studies". Translated and with notes by P. Christopher Smith. New Haven; London: Yale University Press, 1976. . "Dialogue and Dialectic: Eight Hermeneutical Studies on Plato". Translated and with notes by P. Christopher Smith. New Haven; London: Yale University Press, 1980 .

. "Gesammelte Werke 1- Band 1 - Hermenutik I - Wahrheit und Methode: Grunzüge einer philosophischen Hermeneutik". Tübingen: J.B.C. Mohr (Paul Siebeck), 1990. 
. "Hans-Georg Gadamer on Education, Poetry, and History". Edited by Dieter Misgeld and Graeme Nicholson. Translated by Lawrence Schmidt and Monica Reuss. New York: State University of New York Press, 1992.

"Reason in the Age of Science". Translated by Frederick G. Lawrence. Cambridge: MIT Press, 1998.

. "Da palavra ao conceito: a tarefa hermenêutica enquanto filosofia". In: C. Almeida; H. G. Flickinger; L. Rohden (orgs.). Hermenêutica filosófica: nas trilhas de Hans-Georg Gadamer. Porto Alegre: Edipucrs, 2000. p. 13-26.

HADOT, P. “Exercises Spirituels et Philosophie Antique”. 10. ed. revue et augmentée. Paris: Études Augustiniennes, 1987.

HEIDEGGER, M. "On the Way to Language". Translated by Peter D. Hertz. New York: Harper \& Row, 1982.

. "Hegel's Phenomenology of Spirit". Translated by Parvis Emad and Kenneth May. Bloomington; Indianapolis: Indiana University Press, 1988.

HEISIG, J. W. "Philosophers of Nothingness: An Essay on the Kyoto School". Honolulu: University of Hawai'i Press, 2001.

HEISIG, J. W.; KASULIS; T. P; MARALDO, J. C. (eds.). "Japanese philosophy: a sourcebook". Honolulu: University of Hawai'i Press, 2011.

JOHNSON, D. W. "Perception, Expression, and the Continuity of Being: Some Intersections between Nishida and Gadamer". Asian Philosophy, v. 24, n. 1, pp. 4866, 2014.

LIN, C-K. "Truth and Method in the Samdhinirmocana Sūtra". Journal of Chinese Philosophy,v. 37, n. 2, pp. 261-275, June 2010.

MARALDO, J. "Nishida Kitarō". Stanford Encyclopedia of Philosophy. 2012. Disponível em http://plato.stanford.edu/entries/nishida-kitaro/\#PurExp. Acessado em 13 de novembro de 2014.

MARTINS, N. S. “O léxico de Guimarães Rosa”. 3. ed. revista. São Paulo: Editora da Universidade de São Paulo, 2008.

MÜLLER, M. L. "Negatividade dialética e a 'autodeterminação do nada absoluto"”. In: A. Florentino Neto; O. Giacoia Jr. (orgs.). O Nada absoluto e a superação do niilismo: Os fundamentos filosóficos da Escola de Kyoto. Campinas: PHI, 2013. pp. 21-50.

NISHIDA, K. "Intelligibility and the Philosophy of Nothingness: Three Philosophical Essays". Translated with an introduction by Robert Schinzinger. Honolulu: East-West Center Press, 1966.

. "Fundamental Problems of Philosophy": The World of Action and The Dialectical World. Translated with an introduction by David A. Dilworth. Tokyo: Sophia University Press, 1970.

. "An Inquiry into the Good". Translated by Masao Abe and Christopher Ives.

New Haven: Yale University Press, 1990. 
PALMER, R. E. “The Relevance of Gadamer's Philosophical Hermeneutics to ThirtySix Topicsor Fields of Human Activity" - A Lecture Delivered at the Department of Philosophy Southern Illinois University at Carbondale, April 1, 1999.

. "Gadamer and Confucius: Some Possible Affinities". Journal of Chinese Philosophy, Vol. 33, Nr. 1, pp. 81-93, 2006.

PLATÃO. "Plato in Twelve Volumes, Vol. 1 - Euthyphro, Apology, Crito, Phaedo". Translated by Harold North Fowler; Introduction by W.R.M. Lamb. Cambridge: Harvard University Press; London, William Heinemann Ltd., 1966.

. "Plato in Twelve Volumes, Vol. 7 - Epistles". Translated by R.G. Bury. Cambridge: Harvard University Press; London, William Heinemann Ltd. 1966. . "Plato in Twelve Volumes, Vol. 8 - Alcibiades 1, Alcibiades 2, Hipparcus, Lovers, Theages, Charmides, Laches, Lysis". Translated by W.R.M. Lamb. Cambridge: Harvard University Press; London, William Heinemann Ltd., 1955.

. "Platonis Opera, Vol. I - Euthyphro, Apologia Socratis, Crito, Phaedo, Cratylus, Theaetetus, Sophista, Politicus". Greek texts ed. by John Burnet. Oxford: Oxford University Press, 1905. (5 Vol.).

. "Platonis Opera, Vol. II - Parmenides, Philebus, Symposium, Phaedrus, Alcibiades I, Alcibiades II, Hipparchus, Amatores". Greek texts ed. by John Burnet. Oxford: Oxford University Press, 1910. (5 Vol.).

. "Platonis Opera, Vol. V - Minos, Leges, Epinomis, Epistulae". Greek texts ed. by John Burnet. Oxford: Oxford University Press, 1913. (5 Vol.).

"Plato in Twelve Volumes, Vol. 12 - Cratylus, Theaetetus, Sophist, Statesman". Translated by Harold N. Fowler. Cambridge: Harvard University Press; London: William Heinemann Ltd., 1921.

RYŌSUKE, Ō. "O sentido da filosofia de Nishida na história da filosofia". In: A. Florentino Neto; O. Giacoia Jr. (orgs.). Budismo e filosofia em diálogo. Campinas: PHI, 2014. pp. 289-316.

ROCKMORE, T. "Cognition: An Introduction to Hegel's Phenomenology of Spirit". Los Angeles: University of California Press, 1997.

ROHDEN, L. "Hermenêutica filosófica: entre a linguagem da experiência e a experiência da linguagem". São Leopoldo: Ed. Unisinos, 2002.

" "Hermenêutica metodológica e hermenêutica filosófica". Filosofia Unisinos, Vol. 4, Nr. 6, pp. 109-132, Jan./Jun. 2003.

. "Hermenêutica filosófica: entre Heidegger e Gadamer". Natureza Humana, Vol. 14, Nr. 2, pp. 14-36, 2012a.

"Filosofando com Gadamer e Platão: Movimentos, momentos e método[s] da dialética". Dissertatio, Vol. 36, pp. 105-130, 2012 b.

ROSA, J. G. "Grande Sertão: Veredas". 2. ed. Rio de Janeiro: José Olympio, 1958.

. "João Guimarães Rosa: correspondência com seu tradutor italiano Edoardo Bizzari”. 3. ed. Rio de Janeiro: Nova Fronteira, 2003. 
SCHMIDT, D. J. "On the Idiom of Truth and the Movement of Life: Some Remarks on the Task of Hermeneutics". In: G. Figal (Hg.). Internationales Jahrbuch für Hermeneutik. Tübingen: Mohr Siebeck, 2011. pp. 41-53. $35-48,2012$. "On the sources of ethical life". Research in Phenomenology, Vol. 42, pp. "Between word and image: Heidegger, Klee, and Gadamer on gesture and genesis". Bloomington: Indiana University Press, 2013.

SHIELDS, J. M. "Critical Buddhism: Engaging with Modern Japanese Buddhist Thought". Burlington; Farnham: Ashgate Publishing Company, 2011.

STERN, R. "Routledge Philosophy Guidebook to Hegel and the Phenomenology of Spirit". London; New York: Routledge, 2001.

TANABE, H. "Philosophy as metanoethics" Translated by Takeuchi Yoshinori, with Valdo Viglielmo and James W. Heisig. Berkeley; Los Angeles: University of California Press, 1986.

THURMAN, R. A. F. "Buddhist Hermeneutics". Journal of the American Academy of Religion, Vol. 46, Nr. 1, pp. 19-39, March 1978.

WRIGHT, K. "Chapter 12: Gadamer's Philosophical Hermeneutics and New Confucianism". In: F. J. Mootz III; G. H. Taylor (eds.). Gadamer and Ricoeur: Critical Horizons for Contemporary Hermeneutics. London; New York: Continuum International Publishing Group, 2011. (Continuum Studies in Continental Philosophy). pp. 241-264.

YOSHINORI, T. "The Philosophy of Nishida”. In: F. Franck (ed.). The Buddha Eye: An Anthology of the Kyoto School and its Contemporaries. Bloomington: World Wisdom, 2004. pp. 183-208. 